\title{
Does an Information Service Provider Improve the Market?
}

\author{
Kenju Akai ${ }^{1}$, Keiko Aoki ${ }^{2}$, and Nariaki Nishino ${ }^{1}$ \\ ${ }^{1}$ Graduate School of Engineering, The University of Tokyo, Tokyo, Japan \\ akai@css.t.u-tokyo.ac.jp, nishino@tmi.t.u-tokyo.ac.jp \\ ${ }^{2}$ Institute of Social and Economic Research, Osaka University, Osaka, Japan \\ k_aoki@iser.osaka-u.ac.jp
}

\begin{abstract}
This study aims to theoretically analyze whether the information service provider improves the market efficiency. We construct a model where a good supplied by a producer has a risk to be harmful for a consumer because of an accident and it brings monetary losses to both consumers and producers. The accident risk is endogenously determined by the efforts of producers and consumers and the information of safety provided by the producers. The information service provider requires producers to provide information and certifies the credibility of information. In the equilibrium, if the entry cost for the information service provider is small, the optimal effort levels spent by the consumer and producer increase and the risk of accident decreases, which improves the market efficiency.
\end{abstract}

Keywords: Information, Service provider, Double moral hazard, Safety.

\section{Introduction}

There are several goods including the risk of accidents such as rental car and agricultural products. In these goods, trading is one-shot but it sometimes damages, injures, and makes consumers harmful caused by the accident after the trading and consumption. Consumers can not completely estimate the risk of that good holding. The information of risk and how to treat the good provided by the producer make the consumer pay attention to treat those goods as safety and decrease the risk of accidents. For instance, Product liability (PL) low requires the producers to provide the information how to treat the goods for the consumers.

The information enhances the effort of consumers and reduces not only their damages but also damages or losses for the producers because produces need to pay some compensation to the consumers after the accident or lose the reputation and credibility of their goods. The producer often imposes the cost of providing the information to the consumers. Thus, the producer face the tradeoff cost of providing information and reducing the damage. Additional issue for the producer is trust for the consumers. Even if the producer provides the information, the consumers cannot trust it unless there is a system to monitor the producers' deception. Given this situation, 
the producer does not have an incentive to provide the information since it imposes the cost for non-validity information.

This situation allows information service providers to enter the market and intermediate the information from the producers to the consumers. It requires the producer to provide the information and certifies the validity of the information by paying the monitoring cost. The certified information has a validity that the consumer can trust enough. In this case, the producer has an incentive to incur cost of providing the information. The information service provider imposes the fee of using information both to the consumer and producer to finance their monitoring and certification costs. Both the consumers and producers have incentives to pay this fee if their utility and profits becomes better than the case with no-information.

This study constructs a theoretical model and examines whether the information service provider enhances the effort of producers and consumers and the service provider can make a profit in that market. Our prediction is that the information service provider has an incentive to voluntary enter the market to intermediate the information of safety from the producer to the consumer, which improves the market efficiency.

The situation considered in this study is one of the central issues in the market failure caused by the imperfect information that is called double moral hazard in Economics. In this situation, consumers and producers spend less effort levels than the social optimal levels since the imperfect monitoring causes free riding other's efforts. The seminal paper in this issue is Cooper and Ross (1985) and it has been studied by many researchers (for instance; Bhattacharyya \& Lafontaine, 1995; Kim \& Wang, 1998; Martimort, \& Sand-Zantman, 2006). It is also applied to the supply chain (Corbett, C., DeCroix, G., \& Ha, A. (2005a); Ha, A., \& Tong, S. (2008); Zhou, J., Zhao, X., Xue, L., \& Gargeya, V. (2012)) and food service (Elbasha \& Riggs, 2003; Steiner, B., 2012). This study expands the model developed by Elbasha and Riggs (2003) and introduce the information service provider who requires the producers to provide the information of safety for the goods and certifies the validity of the information.

The remaining paper is organized as follows. Section 2 explains the model description and notations. Section 3 theoretically analyzes the equilibrium. Section 4 shows the numerical solutions, and Section 5 summarizes the conclusions and discussions.

\section{Model Description and Notations}

This study modifies the assumption developed by Elbasha and Riggs (2003). It assumes that there are a consumer and a producer in the market. The producer supplies a good and a consumer consumes it. Let $L_{c}$ be the level of costs incurred for which the consumer is not compensated and $L_{f}$ be the losses incurred by the producer. Total costs caused from the accident during using this service (time lost from work, lost product, legal fees, medical costs, pain, and suffering, etc) are denoted by $L$. A good supplied by the producer has a risk to be harmful to the consumer with a given probability of accident, 


$$
\theta=1-\frac{(e+i+\chi)(m+i+\chi)}{a}
$$

where, $e \in[0,1]$ and $m \in[0,1]$ are the levels of efforts expended by the consumer and the producer, respectively. $i \in[0,1]$ is denoted as a information parameter the information service provider provide. The remaining variable, $\chi$, is an potential factor for preventing the accident. As the producer and/or consumer increases their efforts, the risk of accident decreases.

This study assumes that the consumer and the producer are both risk neutral and maximize their own payoffs. The assumption of risk neutrality is made here only to simplify the analysis and not to minimize the importance of risk aversion in the service issue. It assumes that both the consumer and the producer are price-takers in the market for the service, $q$, which is sold at price, $p$. There are two justifications for making this assumption. First, assuming that the consumer is price taker is a standard assumption that is commonly made in the economic literature. Second, the assumption of price-taking behavior on the producer's side is synonymous to assuming a perfectly competitive service markets. Modeling the service market as an imperfect competition is more realistic and may lead to richer conclusions, but it is tangential to the purpose of this paper. For simplicity, we exclude the case where the producer has some market power.

The consumer receives utility $V(q)$ from consuming the service $q$ when it does not make her injured. The utility increases with $q$, but the marginal utility is diminishing. Hence, this model assumes that the utility function is strictly concave. The consumer also receives utility from the remaining money after consuming the good. This utility is given by the term $y-p q$, where $y$ denotes the consumer's income. This model also simplifies the assumption such that the amount of goods consumed does not affect the probability of accident from using the good and the associated losses. Hence, the function $\theta(e, m, i)$ is independent of $q$. Disutility to the consumer arises from exerting efforts to prevent accidents. Such efforts include getting information and adhering to proper maintenance efforts during consumption of that good. Poor preparations and handling practices cause the accident. Let $g(e)=\frac{1}{2} e^{2}$ denote the disutility from exerting efforts to handle and prepare the good properly.

This model also assume that the producer incurs cost from productions, $C(q)=$ $\frac{1}{2} q^{2}$ and cost from implementing safety measures, $H(m)=\frac{1}{2} m^{2}$. For simplicity, this study focuses on the case where the good and its safety are jointly produced. This study assumes that the cost function of providing information incurred by the producer is $C(i)=\frac{1}{b} i^{2}$.

Both players need to pay a fee for using the information service provider. Let $F_{c}$ denote a fee that the consumer pays and $F_{p}$ a fee that the producer pays. This model assumes that these fees are lump-sum. The service provider monitors the information provided by the producers and certifies it as the information label by spending cost denoted as $t(i)=\frac{1}{d} i^{2}$. The service provider also imposes the entry cost, $k$.

Based on this assumption, Section 3 considers the case where the information service provider does not exist and consumer cannot receive the information of the 
good's safety. Then, Section 4 considers the case where the information service provider enters the market and consumer can receive the information provided by the producer.

\section{Non-existence of Information Service Provider}

This sections considers the case that the service provider does not exist and no information is provided, that is, $i=0$. Therefore, the consumer maximizes the following expected utility for given :

$$
E U^{0}=y-p q+V(q)-\theta(e, m, i) L_{c}-g(e)=A-\left\{1-\frac{(e+\chi)(m+\chi)}{a}\right\} L_{c}-\frac{e^{2}}{2}
$$

where $A=y-p q$.

The first-order condition is

$$
e=\frac{(m+\chi) L_{c}}{a}
$$

Simultaneously, the producer maximizes the following expected profits for given e :

$$
E \Pi_{p}^{0}=p q-C(q)-\theta(e, m, i) L_{f}-H(m)=B-\left\{1-\frac{(e+\chi)(m+\chi)}{a}\right\} L_{f}-\frac{m^{2}}{2}
$$

where $B=p q-\mathrm{C}(\mathrm{q})$.

The first-order condition is

$$
m=\frac{(e+\chi) L_{f}}{a}
$$

Then, we obtain the Nash equilibrium as the below:

$$
e^{0}=\frac{\chi L_{c}\left(a+L_{f}\right)}{a^{2}-L_{c} L_{f}}, \quad m^{0}=\frac{\chi L_{f}\left(a+L_{c}\right)}{a^{2}-L_{c} L_{f}}
$$

Next we consider the first best outcomes in this society. We define the social welfare function, $W$, as the sum of the consumer's expected utility and the producer's expected profits. If the government aims to maximize the social welfare, it solve the following expected welfare:

$$
E W^{0}=E U^{0}+E \Pi^{0}=A+B-\left\{1-\frac{(e+\chi)(m+\chi)}{a}\right\} L-\frac{e^{2}}{2}-\frac{m^{2}}{2}
$$

The first-order condition is

$$
\begin{aligned}
& e=\frac{(m+\chi) L}{a} \\
& m=\frac{(e+\chi) L}{a}
\end{aligned}
$$

We obtain the first best outcome which maximize the social welfare

$$
e_{F B}^{0}=\frac{\chi L}{a-L}, \quad m_{F B}^{0}=\frac{\chi L}{a-L}
$$




\section{$4 \quad$ An Existence of Information Service Provider}

Here we consider the information service provider requires the producer to provide the information of good's safety and how to treat it as safety and then it certifies the validity of the information. The consumer trusts the information provided by the producer and maximizes the expected utility for given $m$ and $i$ :

$$
\begin{aligned}
E U^{i}=y-p q+ & V(q)-\theta(e, m, i) L_{c}-g(e) \\
= & A-\left\{1-\frac{(e+i+\chi)(m+i+\chi)}{a}\right\} L_{c}-\frac{e^{2}}{2}-F_{c}
\end{aligned}
$$

The first-order condition is

$$
e=\frac{(m+i+\chi) L_{c}}{a}
$$

Simultaneously, the producer maximizes the expected profits for given $e$ and $i$ :

$$
\begin{aligned}
E \Pi_{p}=p q-C(q) & -\theta(e, m, i) L_{f}-H(m)-c(i)-F_{p} \\
= & B-\left\{1-\frac{(e+i+\chi)(m+i+\chi)}{a}\right\} L_{f}-\frac{m^{2}}{2}-\frac{i^{2}}{b}-F_{p}
\end{aligned}
$$

The first-order condition is

$$
m=\frac{(e+i+\chi) L_{f}}{a}
$$

We obtain the Nash equilibrium, given $i$ as the below.

$$
e^{i}=\frac{(i+\chi) L_{c}\left(a+L_{f}\right)}{a^{2}-L_{c} L_{f}}, \quad m^{i}=\frac{(i+\chi) L_{f}\left(a+L_{c}\right)}{a^{2}-L_{c} L_{f}}
$$

Given this equilibrium strategy, now the service provider decides the fees to maximize its expected profit function under the individual rationality condition of consumers and producers.

$$
E \Pi_{s}=F_{c}+F_{p}-t(i)=F_{c}+F_{p}-\frac{i^{2}}{d}-k
$$

subject to

$$
\begin{gathered}
E U^{i}=A-\left\{1-\frac{\left(e^{i}+i+\chi\right)\left(m^{i}+i+\chi\right)}{a}\right\} L_{c}-\frac{e^{i^{2}}}{2}-F_{c} \\
>E U^{0}=A-\left\{1-\frac{\left(e^{0}+\chi\right)\left(m^{0}+\chi\right)}{a}\right\} L_{c}-\frac{e^{0^{2}}}{2} \\
E \Pi_{p}^{i}=B-\left\{1-\frac{\left(e^{i}+i+\chi\right)\left(m^{i}+i+\chi\right)}{a}\right\} L_{f}-\frac{m^{i^{2}}}{2}-\frac{i^{2}}{b}-F_{p} \\
>E \Pi_{p}^{0}=B-\left\{1-\frac{\left(e^{0}+\chi\right)\left(m^{0}+\chi\right)}{a}\right\} L_{f}-\frac{m^{0^{2}}}{2}
\end{gathered}
$$

The individual rationality conditions for consumers and producers satisfy the conditions such that their utility and profits is not less than the level when the information service provider does not exist. Thus, the service provider can raise the fees equal to the boundary of the individual rationality condition as follows. 


$$
\begin{gathered}
F_{c}=\frac{L_{c}}{a}\left\{\left(e^{i}+i+\chi\right)\left(m^{i}+i+\chi\right)-\left(e^{0}+\chi\right)\left(m^{0}+\chi\right)\right\}-\frac{e^{i^{2}}}{2}+\frac{e^{0^{2}}}{2} \\
F_{p}=\frac{L_{f}}{a}\left\{\left(e^{i}+i+\chi\right)\left(m^{i}+i+\chi\right)-\left(e^{0}+\chi\right)\left(m^{0}+\chi\right)\right\}-\frac{m^{i^{2}}}{2}+\frac{m^{0^{2}}}{2}-\frac{i^{2}}{b}
\end{gathered}
$$

The solution is too complex so that we propose the numerical solutions in the next section and consider whether the information service provider improve the market.

\section{$5 \quad$ Numerical Analysis}

To set the numerical values, we consider the following situation. Let $\chi=1, a=9$, which indicates if the producer and consumer spend the maximum value of their efforts, the probability of the accident becomes zero. Let $b=d=3$, which means that the cost of providing information of producer is equal to the certification cost of service provider. The producer's profits of selling the good and consumer's benefit after consumption of the good is equal to $1, A=B=1$, which are the numeral values as the money. The damage caused from the accident imposes the same losess to the consumer and producer, $L_{c}=L_{f}=1$. But we remain the entry cost $k$ as the variable to discuss the incentives of entry for the service provider.

Thus, we obtain the outcomes in the model without service provider as follows:

$$
\begin{array}{cc}
e^{0}=\frac{1}{8}, & m^{0}=\frac{1}{8} \\
e_{F B}^{0}=\frac{2}{7}, & m_{F B}^{0}=\frac{2}{7} \\
E U^{0}=\frac{17}{128}, & E \Pi_{p}^{0}=\frac{17}{128}
\end{array}
$$

On the other hand, in the model with service provider, we obtain the outcomes as below.

$$
\begin{gathered}
i=\frac{51}{77}, \quad e^{i}=\frac{16}{77}, \quad m^{i}=\frac{16}{77} \\
F_{c}=\frac{17}{128}, \quad F_{p}=\frac{17}{128} \\
E U^{i}=\frac{17}{128}, \quad E \Pi_{p}^{i}=\frac{17}{128}, \quad E \Pi_{s}^{i}=\frac{1581}{4928}-k
\end{gathered}
$$

Comparing the Nash outcomes between two models, the information service provider enhances the effort levels both in the producers and consumers. If the entry cost $k$ is small enough to make the service provider earn the positive profits, since the individual rationality condition for the service provider is satisfied, it can enter the market and the market efficiency is improved.

\section{Conclusion and Discussion}

This paper theoretically analyzes the impact for the information service provider to intermediate the information of good's safety from the producers and consumers. Our 
result shows that the information service provider motivate producers to provide the information of good's safety and raise the effort levels for producer and consumers, which improves the market efficiency.

The original study of Elbasha and Riggs (2003) suggest the tax policy and direct restriction of producers for providing information to improve the market efficiency. In that study, producers are directly restricted to provide the information and it is not motivated by the economic incentives. On the other hand, in our study, the service provider voluntary enters the market and has an incentive to motivate producers to provide the information to finance their monitoring and certification cost. The service provider plays a same role as the government direct restriction.

Notice that the voluntary entry of the service provider is supported by the small entry cost that satisfies its individual rationality. If the entry cost is high, the service provider has no incentive to enter the market. In this case, the government regulation has a power to improve the market.

Our remaining issue is solving the general outcomes instead of specific numerical outcomes. Then, we conduct multi-agent simulation or/and human subject experiments to investigate what factors affect the market improvement when the information service provider exists.

\section{References}

1. Bhattacharyya, S., Lafontaine, F.: Double-sided moral hazard and the nature of share contracts. Rand Journal of Economics 26(4), 761-781 (1995)

2. Cooper, R., Ross, T.: Product Warranties And Double Moral Hazard. Rand Journal of Economics 16(1), 103-113 (1985)

3. Corbett, C., DeCroix, G., Ha, A.: Optimal shared-savings contracts in supply chains: Linear contracts and double moral hazard. European Journal of Operational Research 163(3), 653-667 (2005a)

4. Elbasha, E.H., Riggs, T.L.: The Effect of Information on Producer and Consumer Incentives to Undertake Food Safety Efforts: A Theoretical Model and Policy Implications. Agribusiness 19(1), 29-42 (2003)

5. Ha, A., Tong, S.: Revenue sharing contracts in a supply chain with uncontractible actions. Naval Research Logistics 55(5), 419-431 (2008)

6. Kim, S., Wang, S.: Linear contracts and the double moral-hazard. Journal of Economic Theory 82(2), 342-378 (1998)

7. Martimort, D., Sand-Zantman, W.: Signalling and the design of delegated management contracts for public utilities. Rand Journal of Economics 37(4), 763-782 (2006)

8. Parisi, F.: The harmonization of legal warranties in European sales law: an economic analysis. American Journal of Comparative Law 52(2), 403-431 (2004)

9. Roels, G., Karmarkar, U., Carr, S.: Contracting for Collaborative Services. Management Science 56(5), 849-863 (2010)

10. Steiner, B.: Contracting in the wine supply chain with bilateral moral hazard, residual claimancy and multi-tasking. European Review of Agricultural Economics 39(3), 369-395 (2012)

11. Zhou, J., Zhao, X., Xue, L., Gargeya, V.: Double moral hazard in a supply chain with consumer learning. Decision Support Systems 54(1), 482-495 (2012) 